Int. J. Electrochem. Sci., 14 (2019) $8439-8449$

\title{
Electrochemical Machining of Nickel-based Cast Casing using a Cylindrical Rotating Electrode
}

\author{
Yongcheng Ge $e^{1,2, *}$ Zengwei Zhu ${ }^{2}$ and Yongwei Zhu ${ }^{1}$ \\ ${ }^{1}$ College of Mechanical Engineering, Yangzhou University, Yangzhou, China; \\ ${ }^{2}$ College of Mechanical and Electrical Engineering, Nanjing University of Aeronautics and \\ Astronautics, Nanjing, China; zhuzw@nuaa.edu.cn (Z.Z.); ywzhu@yzu.edu.cn (Y.Z.) \\ *E-mail: zhge@yzu.edu.cn
}

doi: $10.20964 / 2019.09 .01$

Received: 5 April 2019 / Accepted: 8 June 2019 / Published: 31 July 2019

\begin{abstract}
Nickel-based superalloys are a diverse group of materials commonly used for components such as aero engine blades, guides and the cartridge receiver in the hot sections of gas and steam turbines. To satisfy the high-precision manufacturing requirements for engine components, the casting components often need to be processed to remove residual material formed in the casting process. However, with traditional processing methods, the material properties of nickel-based alloys such as high strength at elevated temperatures, high work hardening, and low thermal diffusivity invariably translate into poor machining characteristics. In this study, electrochemical machining (ECM) is employed to remove the casting allowance for a particular design of a simulated cartridge receiver. Two processing methods, designed to achieve a high machining efficiency, were evaluated and the basis for selection of the methods is discussed. Theoretical analysis and simulation results show that a single feed method was more suitable than a cyclic feed method for removal of the casting allowance. Further, it was experimentally demonstrated that the machining accuracy of the single feed method is better than that of the cyclic feed method, and the processing efficiency was also improved significantly for the former.
\end{abstract}

Keywords: Nickel-based superalloys; electrochemical machining; cylindrical electrode; tool trajectory

\section{FULL TEXT}

(C) 2019 The Authors. Published by ESG (www.electrochemsci.org). This article is an open access article distributed under the terms and conditions of the Creative Commons Attribution license (http://creativecommons.org/licenses/by/4.0/). 